\title{
Health Departments' Engagement in Emergency Preparedness Activities: The Influence of Health Informatics Capacity
}

\author{
Gulzar H. Shah*, Bobbie Newell, Ruth E. Whitworth
}

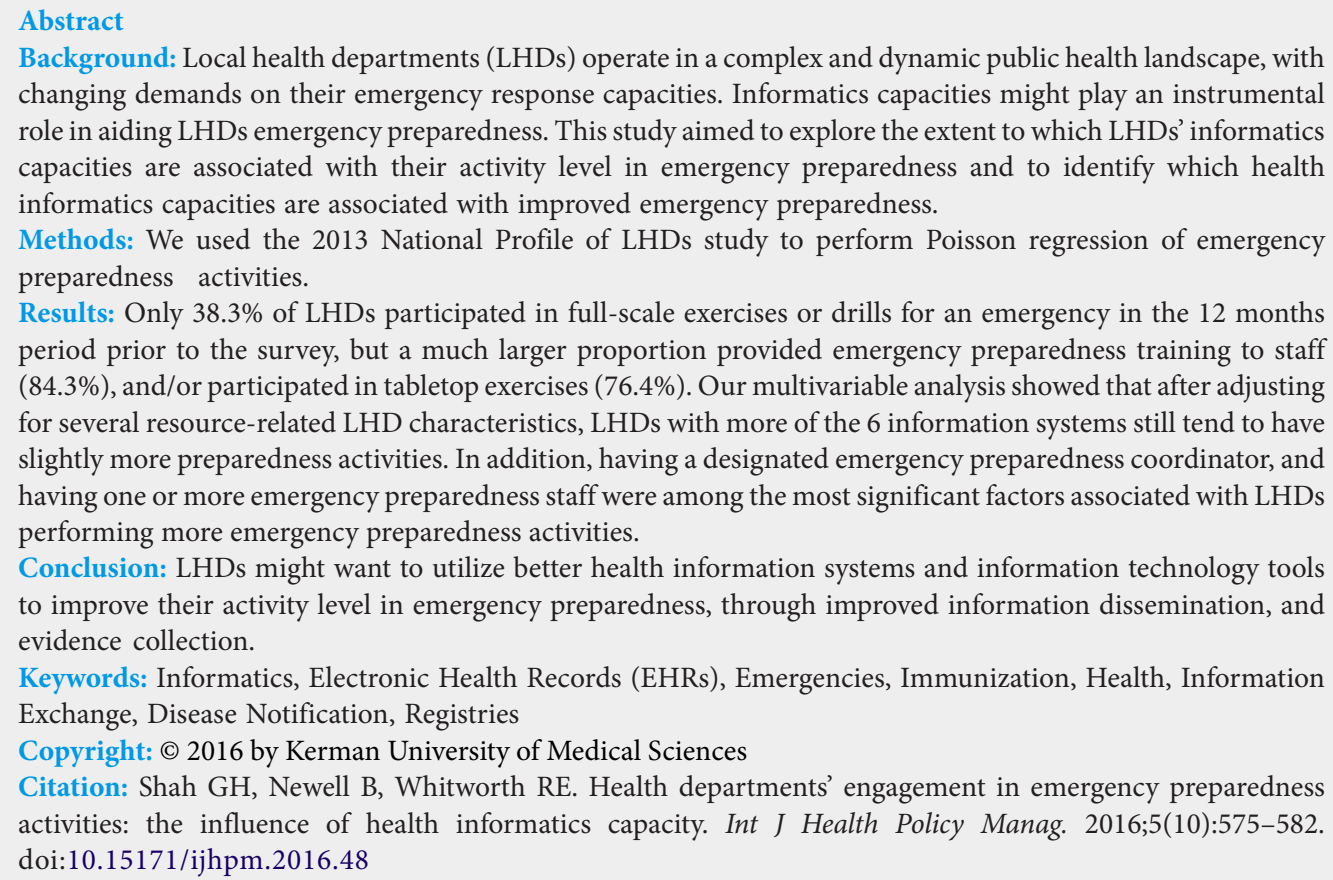

Background: Local health departments (LHDs) operate in a complex and dynamic public health landscape, with changing demands on their emergency response capacities. Informatics capacities might play an instrumental role in aiding LHDs emergency preparedness. This study aimed to explore the extent to which LHDs' informatics capacities are associated with their activity level in emergency preparedness and to identify which health informatics capacities are associated with improved emergency preparedness.

Methods: We used the 2013 National Profile of LHDs study to perform Poisson regression of emergency preparedness activities.

Results: Only $38.3 \%$ of LHDs participated in full-scale exercises or drills for an emergency in the 12 months period prior to the survey, but a much larger proportion provided emergency preparedness training to staff (84.3\%), and/or participated in tabletop exercises (76.4\%). Our multivariable analysis showed that after adjusting for several resource-related LHD characteristics, LHDs with more of the 6 information systems still tend to have slightly more preparedness activities. In addition, having a designated emergency preparedness coordinator, and having one or more emergency preparedness staff were among the most significant factors associated with LHDs performing more emergency preparedness activities.

Conclusion: LHDs might want to utilize better health information systems and information technology tools to improve their activity level in emergency preparedness, through improved information dissemination, and evidence collection.

Keywords: Informatics, Electronic Health Records (EHRs), Emergencies, Immunization, Health, Information Exchange, Disease Notification, Registries

Copyright: (C) 2016 by Kerman University of Medical Sciences

Citation: Shah GH, Newell B, Whitworth RE. Health departments' engagement in emergency preparedness activities: the influence of health informatics capacity. Int J Health Policy Manag. 2016;5(10):575-582. doi:10.15171/ijhpm.2016.48

\section{Article History:}

Received: 9 September 2015 Accepted: 23 April 2016 ePublished: 30 April 2016

\section{Key Messages}

Implications for policy makers

- National policies aimed at strengthening public health emergency responses (PHERs) should consider increasing funds dedicated for emergency preparedness activities.

- Full-scale emergency exercises may play an important role in offering emergency staff essential preparation for real-life emergency situations such as disease outbreaks, natural disasters and environmental exposures.

- Health informatics, or systematic use of information technology to improve the public health administrative practices and services, can assist public health agencies to be effective and efficient in emergency preparedness.

- Improving informatics capacities of Local health departments (LHDs) should be a focus of state and national policies, because use of informatics plays an important role in communications and evidence-based decision-making.

- Informatics capacity building is especially important for LHDs in smaller rural jurisdictions that often lack basic infrastructure, both for emergency preparedness and informatics.

Implications for the public

With the United States experiencing more high-impact natural disasters that are harmful to the public's health, lack of efforts to strengthen public health infrastructures for collecting evidence to support surveillance and communications can hurt the general public. The evidence from this research can guide policy-makers about potential gaps in preparedness activities and which modifiable characteristics of public health agencies can be considered in the future interventions.

\section{Introduction}

Local health departments (LHDs) in the United States provide many essential public health services to the communities they serve, including the services crucial for minimizing harm from hazardous events. ${ }^{1}$ Emergency management has historically been the primary responsibility of governmental agencies other than health departments. ${ }^{2}$ In the wake of post 9-11 events and the $2009 \mathrm{H} 1 \mathrm{~N} 1$ pandemic, LHDs as partners in emergency management and response, along with fire and police departments, are expected to have ample capacities to 
respond to unforeseen and increasingly complex hazardous events. ${ }^{2}$ Consequently, preparedness and response capabilities of LHDs have become critically important..$^{2-5}$ Subsequent disasters, such as the H1N1 influenza outbreak that was declared a "pandemic" by the World Health Organization (WHO) in June 2009, make it absolutely imperative for LHDs to have the capacity to work closely with external partners to plan for, respond to, and recover from public health emergencies. ${ }^{6,7}$ In response to various threats, the Centers for Disease Control and Prevention's (CDC's) public health emergency response (PHER) grant for 2009 and 2010 led to short-term increases in emergency preparedness funding for many LHDs. Nevertheless, PHER and the American Recovery and Reinvestment Act (ARRA) funding collectively accounted for merely three percent of total revenues for LHDs, whereas $59 \%$ of LHDs rely exclusively on federal funding for preparedness activities. ${ }^{8}$ While financial support is still inadequate, there has been an increase in persistence and need for the public health agencies to be more aptly prepared to handle emergency situations. ${ }^{1,9}$

LHDs need to maintain close working relationships and communications with other agencies in preparing for and responding to both natural and man-made all-hazards events. ${ }^{10,11}$ Examples of natural disasters include floods, hurricanes, and tornados, and those of man-made hazards include chemical/oil spills, and bioterrorism. Effective and timely exchange of information among LHDs and other emergency response partners is vital for timely communications and generating evidence for efficiently responding to and preparing for all-hazards. Informatics can play an instrumental role in aiding those functions. ${ }^{12}$ Informatics refers to systematic use of information, technology and analytics, to improve the public health administrative practices and services, and is a central driving force for public health agencies to be effective and efficient in delivering quality public health services, particularly in this post-recession era. ${ }^{13-19}$ In the face of funding shortages and heightened demands on LHDs for emergency preparedness, it is important to find evidence to improve public health emergency preparedness. While attacks of 2001 destroyed our sense of security, an aftermath led to the integration of health information exchanges (HIEs) into emergency preparedness and response. ${ }^{20}$ It is argued that informatics capacities such as electronic bio-surveillance and electronic health records (EHRs) may help LHDs to detect potential public health disasters and improve services, thereby promoting and protecting population health. ${ }^{21-23}$ Given the importance of emergency preparedness, it is important to understand LHDs' level of emergency preparedness capacities and whether utilization of health informatics is associated with their degree of emergency preparedness. ${ }^{24}$ To our knowledge, there is a dearth of recent studies that assess this potential association. To fill this evidence gap, we examined the association between LHDs' health informatics capacity and emergency preparedness capacity and identified potential health informatics capacities that might improve the LHDs' emergency preparedness capacity. The underlying assumption is that public health agencies with better informatics capacities should be more capable of accessing real-time data and coordinating and communicating with agencies across areas. ${ }^{19}$ Therefore, we hypothesize that LHDs level of engagement in emergency preparedness activities is influenced by the health informatics capacity.

\section{Methods}

In 2013, the National Association of County and City Health Officials (NACCHO) administered the 2013 National Profile of LHDs Survey, which uses a cross-sectional design to develop a thorough description of organization, infrastructure, services among other characteristics and capabilities of LHDs. ${ }^{21}$ All 2532 LHDs across the country received a core set of questions and a subsample of LHDs received additional questions in the Module 2 about emergency preparedness and informatics capacity. The subsample consisted of 625 LHDs of which 505 LHDs completed the survey (81\% response rate). This sample was selected using stratified random sampling without replacement which assigned LHDs the core survey or core plus one of two modules. ${ }^{22}$ Seven strata were defined by the size of the population in LHD jurisdiction. ${ }^{22}$ Data from the Module 2 of the Profile study were used to operationalize dependent variables related to emergency preparedness activities performed by LHDs and the independent variables reflecting informatics capacities.

\section{Conceptual Framework}

Our primary research hypothesis and selection of informatics capacity as the primary independent variable are guided by the Value of Information perspective. Informed decisionmaking is critical in sorting out competing priorities, and in allocating scant resources. Health informatics can assist with assuring certainty and accuracy of timely information (eg, surveillance improving the efficiency to detect health threats). For instance, accurate and timely information about notifiable diseases can help control infectious diseases and detect and prevent/curb disease outbreaks. ${ }^{25}$ Value of Information is a coherent theoretical framework that can help explain the evidence-based gains that are achieved by adopting new technologies and interventions..$^{24,26-28}$

Public health emergency preparedness is the ability of public health systems such as LHDs, communities, and even individuals to prevent, protect, take action and recuperate from an untimely catastrophic event. ${ }^{29}$ In this study, as outlined by the 2013 NACCHO Profile study, the LHDs' level of emergency preparedness (our dependent variable) is measured by the type of emergency preparedness activities performed. The pertinent question is: "Which of the following emergency preparedness activities has your LHD conducted in the past year?" The activities are: (1) developed or updated a written emergency plan; (2) reviewed relevant legal authorities ${ }^{30}$; (3) participated in tabletop exercises or drills; (4) participated in functional exercises or drills; (5) participated in full-scale exercises or drills; (6) assessed emergency preparedness competencies of staff; and (7) provided emergency preparedness training of staff. According to NACCHO, "a Tabletop Exercise is a scenariobased discussion that permits evaluation of all or portions of the Emergency Operations Plan, through oral interaction and application of plan guidance." ${ }^{31}$ Functional exercise refers to "a scenario-based execution of selected tasks or activities within a functional area of the Emergency Operations Plan. 
It also includes actual movement of people and resources, but includes fewer functions than a full-scale exercise and interaction with outside personnel and functions are simulated." ${ }^{31}$ A full-scale exercise was explained by NACCHO as "a scenario-based exercise that includes all or most of the functions and complex activities of the Emergency Operations Plan. It includes actual movement of people and resources to replicate real world response situations. It is typically conducted under very real-time constraints of an actual incident." ${ }^{11}$ The response categories, identified in the Profile study, for each informatics areas are unchecked (no) or checked (yes). For the multivariable analysis (Poisson regression), we combined these seven categories to calculate the number of activities performed by each LHD, a count variable. The primary independent variable, LHDs' level of implementation of informatics systems was operationalized using the question: "Indicate your LHD's level of activity for each of the following health informatics areas." The question included the following informatics areas: (1) EHRs; (2) HIE; 3) Immunization Registry (IR); (4) electronic disease reporting system (EDRS); (5) electronic lab reporting (ELR); and (6) electronic syndromic surveillance system. EHRs provide access to vital records in times of need and are essential for emergency and disastrous events. ${ }^{32} \mathrm{HIE}$ is the utilization of health information by electronic means to improve healthcare and the overall health status of populations. ${ }^{32}$ The response categories for each IT area were: (a) no activity; (b) have investigated; (c) planning to implement; and $(d)$ have implemented. Categories $(b)$ and $(c)$ were combined to reflect a level of informatics capacity between "no activity" and have implemented. We re-coded these categories into 'have implemented' and 'have not yet implemented.' For the multivariable analyses, we operationalized LHDs' informatics capacity by the number of informatics systems LHDs had predicted. Additional independent variables for the multivariable analyses included indicators of workforce and human resources related to emergency preparedness. These are measured by two variables: whether LHD had a designated emergency preparedness coordinator, and whether LHD had one or more emergency preparedness staff. LHDs' financial resourcefulness is measured by per capita expenditures converted into quintiles (coded as: not reported; quintiles first $<\$ 19$; second $\$ 19-30$; third $\$ 31-46$; fourth $\$ 47-75$; and fifith $\geq 76$ ). LHD's general tendency for evidence-based practice was measured by three practices (which are also Public Health Accreditation Board [PHAB] pre-requisites for accreditation application): conducting a community health assessment (CHA) in the past five years, preparing a formal community health improvement plan (CHIP) in the past five years, and preparing an agencywide strategic plan (SP) within the past five years. LHDs' governance was reflected by two variables, having one or more local boards of health vs. no local boards of health, and a governance category (decentralized or local governance vs. state/shared governance) that reflects the centralization of LHD governance relative to the state health department. In the United States, centralized governance means that LHDs are governed by the state health departments with respect to functions such as hiring and firing the LHD head, developing budget, adopting public health regulations, and making other administrative decisions. Decentralized governance refers to governance authority vested in a governing body at the city, county, or at a level of some other combination of geographic units below the state level. Shared governance implies shared authority. The population of LHDs' jurisdiction was included to control for the scope/scale.

\section{Statistical Analysis}

For each of the independent variables and the items in the dependent variable, we calculated the proportion of LHDs performing given functions or having those characteristics. The Profile study oversamples larger LHDs for the module questions, and the response rates also differ by population size. For all analyses, we used statistical weights to account for the sampling design of the Profile, and disproportionate response rates by size of the population in LHD jurisdiction. We used Somer's D statistics for establishing the significance of association between emergency preparedness activities and the individual independent variables indicating informatics capacity, all dichotomous dependent variables. To isolate the influence of the informatics systems on emergency preparedness activities, after controlling for other influences such as population size, governance type, etc, we used multivariable analysis to perform simultaneous adjustments, which is a notable strength of our study. To this end, we performed multivariable analysis for which the dependent variable was a count variable number of emergency preparedness activities, with values ranging from zero to seven. The proportion of zeroes (3.6\%) was small enough that the zero-inflated option was not used. The count variables such as this can be modeled using Poisson regression in the absence of over-dispersion. The test showed no over-dispersion for our dependent variable (mean $=4.567$; variance $=1.936$ ), therefore, we used Poisson regression (SPSS command GENLIN, with option distribution = Poisson). The Omnibus test showed that after including all independent variables in our model we had statistically significant overall model (ie, likelihood ratio chi-square $=609.388 ; P=.000$ ). All independent variables discussed in the conceptual model were included in the Poisson regression and the adjusted incidence rate ratios (AIRR) were computed with these variables included simultaneously in the model. We carried out all analyses in 2015 using IBM SPSS statistics for Windows, (version 22.0.0.0 Armonk, NY: IBM Corp.).

\section{Results}

Only $38.3 \%$ of LHDs participated in full-scale exercises or drills for an emergency in the 12 months period prior to the survey. An additional infrequent activity was reviewing relevant legal authorities (47.4\%). The most frequently performed emergency preparedness activities included developing or updating a written emergency plan (86.9\%), providing emergency preparedness training to staff $(84.3 \%)$, participation in tabletop exercises or drills (76.4\%), and assessing emergency preparedness competencies of staff (66.4\%). Roughly $66 \%$ of LHDs participated in functional exercises or drills (Table 1).

Table 2 shows the univariate association between individual informatics components and emergency preparedness activities. Having implemented information systems is 
Table 1. Descriptive Statistics for Informatics Capacity, Emergency Preparedness Activities and Covariates

\begin{tabular}{|c|c|c|}
\hline LHD Characteristics & Number (Un-weighted) & Percent (Weighted) \\
\hline \multicolumn{3}{|l|}{ Emergency preparedness activities LHD conducted in the past year } \\
\hline Developed or updated a written emergency plan & 440 & 86.9 \\
\hline Reviewed relevant legal authorities & 252 & 47.4 \\
\hline Participated in tabletop exercises or drills & 399 & 76.4 \\
\hline Participated in functional exercises or drills & 348 & 65.7 \\
\hline Participated in full-scale exercises or drills & 213 & 38.3 \\
\hline Assessed emergency preparedness competencies of staff & 341 & 66.4 \\
\hline Provided emergency preparedness training to staff & 430 & 84.3 \\
\hline None & 11 & 2.8 \\
\hline Other & - & - \\
\hline \multicolumn{3}{|l|}{ LHD's level of activity for each of the following information technology areas } \\
\hline EHR used & 122 & 22.1 \\
\hline HIE & 69 & 13.3 \\
\hline IR & 416 & 82.2 \\
\hline EDRS & 368 & 72.2 \\
\hline ELR & 245 & 46.9 \\
\hline Electronic syndromic surveillance system & 317 & 62.4 \\
\hline \multicolumn{3}{|l|}{ Per capita expenditures } \\
\hline Ist quintile & 87 & 16.7 \\
\hline 2nd quintile & 75 & 13.8 \\
\hline 3rd quintile & 74 & 14.5 \\
\hline 4th quintile & 76 & 14.7 \\
\hline 5th quintile & 61 & 12.1 \\
\hline Not reported & 132 & 28.2 \\
\hline \multicolumn{3}{|l|}{ CHA completed within 5 years } \\
\hline Yes, within 5 years & 363 & 71.6 \\
\hline No but plan to in the next year & 55 & 12.0 \\
\hline No/Not within 5 years AND no plan in the next year & 78 & 16.4 \\
\hline \multicolumn{3}{|l|}{ CHIP completed within 5 years } \\
\hline Yes, within 5 years & 278 & 54.3 \\
\hline No but plan to in the next year & 114 & 23.1 \\
\hline No/Not within 5 years AND no plan in the next year & 104 & 22.7 \\
\hline \multicolumn{3}{|l|}{ SP completed within 5 years } \\
\hline Yes, within 5 years & 239 & 47.3 \\
\hline No but plan to in the next year & 116 & 22.7 \\
\hline No/Not within 5 years AND no plan in the next year & 138 & 30.0 \\
\hline \multicolumn{3}{|l|}{ Decentralized governance } \\
\hline Decentralized & 405 & 79.5 \\
\hline Centralized/shared & 100 & 20.5 \\
\hline \multicolumn{3}{|l|}{ LHD has a designated emergency preparedness coordinator } \\
\hline No & 80 & 18.1 \\
\hline Yes & 425 & 81.9 \\
\hline \multicolumn{3}{|l|}{ LHD has one or more emergency preparedness staff } \\
\hline No & 165 & 38.6 \\
\hline Yes & 340 & 61.4 \\
\hline Population (in 100000 s) & 505 & $1.3(3.7)$ \\
\hline Number of informatics systems used & 493 & $3.0(1.4)$ \\
\hline Number of emergency preparedness activities conducted by LHD in the past year & 505 & $4.6(1.9)$ \\
\hline
\end{tabular}

Abbreviations: LHD; local health department; EHR, electronic health record; HIE, health information exchange; IR, immunization registry; EDRS, electronic disease reporting system; ELR, electronic lab reporting; CHA, community health assessment; CHIP, community health improvement pla; SP, strategic plan.

significantly associated with engagement in preparedness activities. LHDs' that had implemented EHRs had a significantly higher proportion of those that had developed or updated emergency preparedness plans, reviewed relevant legal authorities, held tabletop exercises, functional, and full-scale exercises/drills and participated in exercises/drills. LHDs participating in the HIE (vs. LHDs not participating in HIEs) also had a significantly higher proportion that had developed or updated emergency preparedness plans, reviewed relevant legal authorities, participated in functional exercises/drills, and assessed emergency preparedness staff competencies. Proportion of LHDs that had held tabletop exercises and provided emergency preparedness training to staff was significantly higher for LHDs that maintain an IR compared to those with no IR. Among LHDs with EDRSs, ELR or electronic syndromic surveillance, the proportion performing several emergency preparedness activities was also significantly higher.

To show the impact of informatics capacities after controlling for other variables, we computed AIRR for performing 
Table 2. Percent of Emergency Preparedness Activities LHDs Conducted in the Past Year by LHD's Level of Activity in Information Technology Areas

\begin{tabular}{|c|c|c|c|c|c|c|c|}
\hline \multirow[b]{2}{*}{$\begin{array}{l}\text { LHD's Level of Activity by } \\
\text { Information Technology Areas }\end{array}$} & \multicolumn{7}{|c|}{ Emergency Preparedness Activities LHDs Conducted in the Past Year } \\
\hline & $\begin{array}{c}\text { Developed } \\
\text { Written } \\
\text { Emergency } \\
\text { Plan (\%) }\end{array}$ & $\begin{array}{c}\text { Reviewed } \\
\text { Relevant Legal } \\
\text { Authorities (\%) }\end{array}$ & $\begin{array}{c}\text { Table-Top } \\
\text { Exercises, } \\
\text { Drills-EP } \\
\text { Activity (\%) }\end{array}$ & $\begin{array}{c}\text { Functional } \\
\text { Exercises/Drills- } \\
\text { EP Activity (\%) }\end{array}$ & $\begin{array}{c}\text { Full-Scale } \\
\text { Exercises/ } \\
\text { Drills-EP } \\
\text { Activity (\%) } \\
\end{array}$ & $\begin{array}{l}\text { Assessed EP Staff } \\
\text { Competencies (\%) }\end{array}$ & $\begin{array}{c}\text { Provided EP } \\
\text { Training to } \\
\text { Staff (\%) }\end{array}$ \\
\hline \multicolumn{8}{|l|}{ EHR used } \\
\hline Have implemented & $94.3^{\mathrm{a}}$ & $63.1^{\mathrm{a}}$ & $87.7^{\mathrm{a}}$ & $79.5^{\mathrm{a}}$ & $53.3^{\mathrm{a}}$ & 74.6 & 89.3 \\
\hline $\begin{array}{l}\text { Have investigated or plan to } \\
\text { Implement }\end{array}$ & $87.0^{\mathrm{a}}$ & $51.6^{\mathrm{a}}$ & $80.7^{\mathrm{a}}$ & $70.4^{\mathrm{a}}$ & $41.7^{\mathrm{a}}$ & 68.2 & 86.1 \\
\hline Not implemented & $85.6^{\mathrm{a}}$ & $39.2^{\mathrm{a}}$ & $73.2^{\mathrm{a}}$ & $61.4^{\mathrm{a}}$ & $35.9^{a}$ & 64.1 & 84.3 \\
\hline \multicolumn{8}{|l|}{ HIE } \\
\hline Have implemented & $97.1^{\mathrm{a}}$ & $59.4^{a}$ & 82.6 & $78.3^{\mathrm{a}}$ & 49.3 & $75.4^{a}$ & 89.9 \\
\hline $\begin{array}{l}\text { Have investigated or plan to } \\
\text { Implement }\end{array}$ & $88.6^{a}$ & $61.2^{\mathrm{a}}$ & 82.6 & $75.8^{a}$ & 44.3 & $74.0^{\mathrm{a}}$ & 89.0 \\
\hline Not implemented & $85.2^{\mathrm{a}}$ & $36.7^{\mathrm{a}}$ & 76.7 & $61.0^{\mathrm{a}}$ & 39.0 & $60.5^{\mathrm{a}}$ & 82.4 \\
\hline \multicolumn{8}{|l|}{ IR } \\
\hline Have implemented & $89.6^{a}$ & 50.6 & $83.1^{\mathrm{a}}$ & 71.3 & 44.6 & 69.9 & $88.0^{a}$ \\
\hline $\begin{array}{l}\text { Have investigated or plan to } \\
\text { Implement }\end{array}$ & $91.9^{\mathrm{a}}$ & 64.9 & $73.0^{\mathrm{a}}$ & 70.3 & 37.8 & 75.7 & $89.2^{\mathrm{a}}$ \\
\hline Not implemented & $73.9^{a}$ & 39.1 & $58.7^{\mathrm{a}}$ & 56.5 & 30.4 & 50.0 & $69.6^{a}$ \\
\hline \multicolumn{8}{|l|}{ EDRS } \\
\hline Have implemented & $91.8^{\mathrm{a}}$ & $53.1^{\mathrm{a}}$ & $83.4^{a}$ & $72.2^{\mathrm{a}}$ & 44.1 & $71.7^{\mathrm{a}}$ & $89.1^{\mathrm{a}}$ \\
\hline $\begin{array}{l}\text { Have investigated or plan to } \\
\text { Implement }\end{array}$ & $91.1^{\mathrm{a}}$ & $64.3^{a}$ & $87.5^{\mathrm{a}}$ & $75.0^{\mathrm{a}}$ & 44.6 & $78.6^{a}$ & $89.3^{\mathrm{a}}$ \\
\hline Not implemented & $69.3^{a}$ & $28.0^{\mathrm{a}}$ & $58.7^{\mathrm{a}}$ & $54.7^{\mathrm{a}}$ & 34.7 & $45.3^{a}$ & $70.7^{\mathrm{a}}$ \\
\hline \multicolumn{8}{|l|}{ ELR } \\
\hline Have implemented & $90.6^{a}$ & $52.0^{a}$ & 81.6 & $73.0^{\mathrm{a}}$ & 44.3 & $72.1^{\mathrm{a}}$ & $88.9^{a}$ \\
\hline $\begin{array}{l}\text { Have investigated or plan to } \\
\text { Implement }\end{array}$ & $93.2^{\mathrm{a}}$ & $68.2^{\mathrm{a}}$ & 83.0 & $77.3^{\mathrm{a}}$ & 47.7 & $80.7^{\mathrm{a}}$ & $92.0^{\mathrm{a}}$ \\
\hline Not implemented & $82.5^{\mathrm{a}}$ & $39.2^{\mathrm{a}}$ & 76.5 & $61.4^{\mathrm{a}}$ & 38.0 & $56.6^{a}$ & $79.5^{a}$ \\
\hline \multicolumn{8}{|l|}{$\begin{array}{l}\text { Electronic syndromic } \\
\text { surveillance system used }\end{array}$} \\
\hline No & $82.4^{a}$ & $40.3^{a}$ & $73.2^{\mathrm{a}}$ & $60.7^{a}$ & $35.8^{\mathrm{a}}$ & $62.5^{\mathrm{a}}$ & $81.5^{\mathrm{a}}$ \\
\hline Yes & $90.9^{a}$ & $53.5^{a}$ & $79.3^{a}$ & $70.2^{\mathrm{a}}$ & $39.8^{a}$ & $69.6^{a}$ & $86.1^{\mathrm{a}}$ \\
\hline
\end{tabular}

Abbreviations: EP, emergency preparedness; LHD, local health department; EHR, electronic health record; HIE, health information exchange; IR, immunization registry; EDRS, electronic disease reporting system; ELR, electronic lab reporting.

${ }^{\text {a }}$ Percentages indicate that differences are significant at $P \leq .05$ based on Somers' $D$.

emergency preparedness activities by LHDs in the past year (Table 3). With all factors at the reference level, the model estimates that an agency would perform 3.38 preparedness activities.

The predicted count for emergency preparedness activities performed by LHDs within the past year was significantly higher for LHDs with higher informatics capacity, though the increase in incidence rate was small for each additional informatics capacity $(\mathrm{AIRR}=1.03, P=.000)$. Per capita expenditures had no clear relationship with emergency preparedness activities. Having completed a $C H A$ was not significantly associated with emergency preparedness activities performed by LHDs. The incident rate for emergency preparedness activities was significantly lower in LHDs that had not completed a CHIP within five years and had no plans to do so in the next 12 months, (AIRR $=0.89, P=.001)$ than the incidence rate for LHDs that had completed a CHIP within five years holding the other variables at constant. Absence of a current SP (no SP within five years) and having no plans to complete one in the next year was also significantly associated with lower incidence rate of conducting more emergency preparedness activities $(\mathrm{AIRR}=0.91, P=.000)$ than the incidence rate for
LHDs that had completed a SP within five years. Centralized/ shared governance, compared with decentralized (local) governance was associated with conducting a fewer number of emergency preparedness activities (AIRR $=0.79, P=.000$ ), assuming all other factors were at the reference level. Having a larger population size in LHD jurisdiction was associated with a significantly higher number of emergency preparedness activities assuming all other factors were at the reference level. The incidence rate for performing emergency preparedness activities was significantly greater for LHDs that had one or more emergency preparedness employees than the incidence rate for LHDs with no emergency preparedness staff (AIRR $=1.21, P=.000)$. The presence of the designated emergency preparedness coordinator was associated with an increase of preparedness activities by 1.28 times, assuming all other factors were at the reference level (incident rate ratio $[\mathrm{IRR}]=1.28, \quad P=.000)$.

\section{Discussion}

Our study presents the nationally generalizable empirical evidence concerning LHDs' emergency preparedness capacities and the association with informatics capacity. We 
Table 3. Adjusted Incident Rate Ratios for Number of Emergency Preparedness Activities Conducted by LHD in the Past Year by LHD Characteristics ${ }^{a}$

\begin{tabular}{|c|c|c|c|c|}
\hline \multirow{2}{*}{ LHD Characteristics } & \multirow{2}{*}{ AIRR } & \multicolumn{2}{|c|}{ 95\% Cl for AIRR } & \multirow{2}{*}{$\boldsymbol{P}$} \\
\hline & & Lower Bound & Upper Bound & \\
\hline Number of information systems (ELR, HIE, IR, EDRS, ELR, ESS) implemented by LHD & 1.03 & 1.02 & 1.05 & $.000^{\mathrm{b}}$ \\
\hline \multicolumn{5}{|l|}{ Per capita expenditures } \\
\hline Not reported & 0.94 & 0.88 & 1.00 & $.052^{\mathrm{b}}$ \\
\hline 2nd quintile & 0.95 & 0.89 & 1.02 & .196 \\
\hline 3rd quintile & 0.89 & 0.83 & 0.95 & $.000^{\mathrm{b}}$ \\
\hline 4th quintile & 1.04 & 0.98 & 1.11 & .188 \\
\hline 5th quintile & 1.02 & 0.96 & 1.09 & .549 \\
\hline 1st quintile & - & - & - & - \\
\hline \multicolumn{5}{|l|}{ CHA completed within 5 years } \\
\hline No/Not within 5 years AND no plan in the next year & 1.04 & 0.96 & 1.12 & .345 \\
\hline No but plan to in the next year & 0.96 & 0.90 & 1.03 & .299 \\
\hline Yes, within 5 years & - & - & - & - \\
\hline \multicolumn{5}{|l|}{ CHIP completed within 5 years } \\
\hline No/Not within 5 years AND no plan in the next year & 0.89 & 0.83 & 0.95 & $.001^{\mathrm{b}}$ \\
\hline No but plan to in the next year & 0.97 & 0.92 & 1.03 & .317 \\
\hline Yes, within 5 years & - & - & - & - \\
\hline \multicolumn{5}{|l|}{ SP completed within 5 years } \\
\hline No/Not within 5 years AND no plan in the next year & 0.91 & 0.86 & 0.95 & $.000^{\mathrm{b}}$ \\
\hline No but plan to in the next year & 1.03 & 0.98 & 1.08 & .295 \\
\hline Yes, within 5 years & - & - & - & - \\
\hline \multicolumn{5}{|l|}{ Decentralized governance } \\
\hline Centralized/shared & 0.79 & 0.74 & 0.83 & $.000^{\mathrm{b}}$ \\
\hline Decentralized & - & - & - & - \\
\hline \multicolumn{5}{|l|}{ LHD has a designated emergency preparedness coordinator } \\
\hline Yes & 1.28 & 1.20 & 1.36 & $.000^{\mathrm{b}}$ \\
\hline No & - & - & - & - \\
\hline \multicolumn{5}{|l|}{ LHD has one or more emergency preparedness staff } \\
\hline Yes & 1.21 & 1.16 & 1.27 & $.000^{\mathrm{b}}$ \\
\hline No & - & - & - & - \\
\hline Population in $100000 \mathrm{~s}$ & 1.01 & 1.00 & 1.01 & $.011^{\mathrm{b}}$ \\
\hline Intercept & 3.38 & 3.10 & 3.69 & .000 \\
\hline
\end{tabular}

Abbreviations: AIRR, Adjusted Incident Rate Ratio; LHD; local health department; EHR, electronic health record; HIE, health information exchange; IR, immunization registry; ESS, electronic disease surveillance; EDRS, electronic disease reporting system; ELR, electronic lab reporting; CHA, community health assessment; CHIP, community health improvement pla; SP, strategic plan.

Note: The AIRRs in this table show the incident rate ratio for each of the independent variable, after adjusting for all other independent variables in the model (listed in this table).

${ }^{a}$ Cells with ellipses indicate the reference category.

${ }^{\mathrm{b}} P$ values indicate that the subgroup differences are significant at $P \leq .05$.

expect large, relatively well-resourced HDs to have more of the 6 information systems and more preparedness activities. This study shows that, adjusting for several resource-related HD characteristics, LHDs with more of the 6 information systems still tend to have slightly more preparedness activities. Our finding that only $38 \%$ of the LHDs participated in fullscale exercises or drills for emergency preparedness in the 12 months prior to the survey indicates that this important aspect of LHDs' capacity needs policy attention. Since emergencies, by definition, are shrouded with uncertainty and confusion full-scale emergency exercises offer emergency staff essential preparation for real-life emergency situations. Roughly one-third of LHDs did not routinely assess the emergency preparedness competencies of their staff.

The unadjusted association between the implementation of individual informatics capacities and emergency preparedness activities were significant with one exception (responding to emergency events). Though higher informatics capacities are associated with other emergency preparedness activities, they do not increase the likelihood of the LHDs' participation in responding to an all-hazards event within the past 12 months. This is in line with the premise that although LHDs' informatics capacity might help LHDs perform better when responding to the events, likelihood of hazardous situations presenting themselves (and necessitating LHDs to participate) should have little to do with the LHDs ability/preparedness to respond.

Our multivariable analysis also supported the premise that LHDs with higher informatics capacity are more likely to be engaged in greater number of emergency preparedness activities in the 12-month period. These emergency preparedness activities included: having developed or updated a written emergency plan, reviewed relevant legal authorities, participated in tabletop exercises or drills, participated in functional exercises or drills, participated in full-scale exercises or drills, assessed emergency preparedness competencies of staff, and provided emergency preparedness training of staff.

Our findings suggest that LHDs with no emergency preparedness coordinator and a smaller emergency preparedness staff might need assistance in developing or improving these resources. Decentralized LHDs are also 
more likely to have performed more emergency preparedness activities. It is likely, however, that the lack of emergencypreparedness is a function of lack of demand for centralized LHDs, as state health agencies might provide these functions for the LHDs that are units of their operations. Lower engagement in emergency preparedness by LHDs in smaller jurisdictions might indicate a reflection of lower demand for such services for those LHDs.

There are a few limitations to this study. Some LHDs' engagement in emergency preparedness might depend allotment of a discretionary budget for specific activities related to emergency preparedness. Our research design, dependent upon the secondary cross-sectional data, does not allow determination of a causal relationship between the informatics capacity and emergency preparedness activities, as there was no lag time between the independent variables and the dependent variable. The Profile study data does not capture the scale and scope of the informatics activities as well as the emergency preparedness activities. In addition, these capacities are self-reported and are not independently verified. Based on the staff involved in responding to Profile survey (eg, LHD administration/leadership as opposed to programmatic staff), their interpretation might have fluctuated with respect to content, quality, and scope of their LHD's informatics capacities and emergency activities. Our study also treated each of the emergency activities equally in importance in our multivariable analysis. Future researchers, assessing the value of LHD participation in emergency preparedness activities, may consider applying proper importance weights to each of these activities, based on an expert panel's input. Perhaps a more important area of future research is to explore whether LHDs with particular areas of informatics strength are better at responding to various emergency preparedness events, and manner in which those informatics capacities contribute to emergency management while responding to actual events. This research would require primary data, collected using a combination of qualitative and quantitative approaches. The result is small enough that it could be from residual confounding.

\section{Conclusion}

LHDs with more of the 6 information systems have better informatics, which may increase their preparedness capacity. Our findings also show which emergency preparedness activities LHDs performed less often and could require policy intervention. Our research showed a significant association between health informatics capacity of LHDs and their performance of emergency preparedness activities, indicating that LHDs might want to harness better health information systems and information technology tools to support communication needs, and information gathering or dissemination, when preparing for and responding to disastrous/emergency events. The recent Ebola crisis is a perfect example in our lack of harnessing informatics capacity to share and use information, and coordinate our responses to improve emergency preparedness and response. ${ }^{33}$ The ability to communicate is listed as one of the 15 capabilities developed by the $\mathrm{CDC}^{3,31}$ and is a major indicator of success in preparedness efforts. ${ }^{34}$ Our findings can inform efforts to improve emergency preparedness capacity, as we are experiencing more high-impact natural disasters that are harmful to the public's health.

\section{Acknowledgements}

The authors are thankful to NACCHO, Washington, DC, USA for sharing the Profile study data for this publication. For this research manuscript, the authors did not receive any funding.

\section{Ethical issues}

The research protocol was reviewed by the Georgia Southern University IRB, Statesboro, GA, USA and was exempt from full review.

\section{Competing interests}

Authors declare that they have no competing interests.

\section{Authors' contributions}

GHS obtained the data, performed analyses, and wrote results. BN took a lead in review of literature on emergency preparedness and REW performed literature review for health informatics. All three authors contributed to discussion and conclusions.

\section{References}

1. Nguh J. The role of information technology in emergency preparedness by local health departments: a literature review. $J$ Emerg Manag. 2014;12(4):327-339. doi:10.5055/jem.2014.0183

2. Haddow G, Bullock J, Coppola, DP. Introduction to Emergency Management. Newton: MA, Butterworth-Heinemann; 2013.

3. Schoch-Spana M, Selck FW, Goldberg LA. A national survey on health department capacity for community engagement in emergency preparedness. J Public Health Manag Pract. 2015;21(2):196-207.

4. Cantey PT, Chuk MG, Kohl KS, et al. Public health emergency preparedness: lessons learned about monitoring of interventions from the National Association of County and City Health Official's survey of nonpharmaceutical interventions for pandemic H1N1. J Public Health Manag Pract. 2013;19(1):70-76. doi:10.1097/ phh.0b013e31824d4666

5. Stoto MA. Regionalization in local public health systems: variation in rationale, implementation, and impact on public health preparedness. Public Health Rep. 2008;123(4):441-449.

6. Kmietowicz Z. WHO declares that H1N1 pandemic is officially over. BMJ. 2010;341: c4393. doi:10.1136/bmj.c4393

7. Zarocostas J. H1N1 pandemic flu found to cause viral pneumonia in severe cases, says WHO. BMJ. 2009;339:b4313. doi:10.1136/ bmj.b4313

8. Shah GH, Herrmann J, DrabczykA, Fisher S, Leep C. Local public health emergency preparedness: situation of funding, types of hazard events responded to and involvement of volunteers. Poster presented at the 2011 Public Health Preparedness Summit. Feb 22-25, Atlanta, Georgia; 2011.

9. Nguh J. Have Maryland local health departments effectively put in place the information technology relevant to emergency preparedness? J Emerg Manag. 2012;11(1):73-91.

10. Chamberlain AT, Seib K, Wells K, et al. Perspectives of immunization program managers on 2009-10 H1N1 vaccination in the United States: a national survey. Biosecur Bioterror. 2012;10(1):142-150. doi:10.1089/bsp.2011.0077

11. Rosenfeld LA, Etkind P, Grasso A, Adams AJ, Rothholz MC. Extending the reach: local health department collaboration with community pharmacies in Palm Beach County, Florida for H1N1 influenza pandemic response. J Public Health Manag Pract. 2011;17(5):439-448. doi:10.1097/phh.0b013e31821138ae

12. Gotham IJ, Sottolano DL, Hennessy ME, et al. An integrated 
information system for all-hazards health preparedness and response: New York State Health Emergency Response Data System. J Public Health Manag Pract. 2007;13(5):486-496. doi:10.1097/01.phh.0000285202.48588.89

13. Yasnoff WA, O'Carroll PW, Koo D, Linkins RW, Kilbourne EM. Public health informatics: improving and transforming public health in the information age. J Public Health Manag Pract. 2000;6(6):67-75. doi:10.1097/00124784-200006060-00010

14. Choo CW. The knowing organization: How organizations use information to construct meaning, create knowledge and make decisions. Int J Inf Manage. 1996;16(5):329-340.

15. Baker EL, Ross DA. Managing Information-Addressing a Central Challenge of the Public Health Enterprise. J Public Health Manag Pract. 2013;19(4):383-385. doi:10.1097/ phh.0b013e318296f43f

16. Magruder C, Burke M, Hann NE, Ludovic JA. Using information technology to improve the public health system. J Public Health Manag Pract. 2005;11(2):123-130. doi:10.1097/00124784200503000-00005

17. Lumpkin JR, Magnuson J. History and significance of information systems and public health. In: Magnuson JA, FU PC, eds. Public Health Informatics and Information Systems. 2nd ed. London: Springer; 2014:19-36.

18. Willard R, Shah GH, Leep C, Ku L. Impact of the 2008-2010 economic recession on local health departments. J Public Health Manag Pract. 2012;18(2):106-114. doi:10.1097/ phh.0b013e3182461cf2

19. Carman AL, Timsina LR, Scutchfield FD. Quality improvement activities of local health departments during the 2008-2010 economic recession. Am J Prev Med. 2014;46(2):171-174. doi:10.1016/j.amepre.2013.10.005

20. Burke RV, Ryutov T, Neches R, Upperman J. Health informatics for pediatric disaster preparedness planning. Appl Clin Inform. 2010;1(3):256-264. doi:10.4338/aci-2009-12-r-0019

21. Novick LF, Morrow CB, Mays GP. Public Health Administration. Sudbury, MA: Jones and Bartlett; 2008.

22. Smith PF, Hadler JL, Stanbury M, Rolfs RT, Hopkins RS. "Blueprint version 2.0": updating public health surveillance for the 21st century. J Public Health Manag Pract. 2013;19(3):231239. doi:10.1097/phh.0b013e318262906e
23. McCullough MJ, Zimmerman FJ, Bell DS, Rodriguez HP. Local public health department adoption and use of electronic health records. J Public Health Manag Pract. 2015;21(1):E20-E28. doi:10.1097/phh.0000000000000143

24. Tornatzky L FM. The Process of Technology Innovation. Lexington, MA: Lexington Books; 1990.

25. Boehmer TK, Patnaik JL, Burnite SJ, Ghosh TS, Gershman K, Vogt RL. Use of hospital discharge data to evaluate notifiable disease reporting to Colorado's Electronic Disease Reporting System. Public Health Rep. 2011;126(1):100-106.

26. Meltzer DO, Hoomans T, Chung J, Basu A. Minimal modeling approaches to value of information analysis for health research. Med Decis Making. 2011;31(6):E1-E22. doi:10.1177/0272989X11412975

27. Steuten L, van de Wetering G, Groothuis-Oudshoorn K, Retel V. A systematical and critical review of the evolving methods and applications of value of information in academia and practice. Pharmacoeconomics. 2013;31(1);25-48. doi:10.1007/s40273012-0008-3

28. Tuffaha HW, Gordon L, Scuffham PA. Value of information analysis in oncology: the value of evidence and evidence of value. J Oncol Pract. 2014;10(2):e55-e62. doi:10.1200/ JOP.2013.001108

29. Kmietowicz Z. WHO declares that H1N1 pandemic is officially over. BMJ. 2010;341.

30. Weiner EE, Trangenstein PA. Informatics solutions for emergency planning and response. Stud Health Technol Inform. 2007;129(Pt 2):1164-1168.

31. NACCHO. Profile Study Instruments \& Codebooks. http:// nacchoprofilestudy.org/data-requests/. Accessed December 18, 2015.

32. Savoia E, Lin L, Viswanath K. Communications in public health emergency preparedness: a systematic review of the literature. Biosecur Bioterror. 2013;11(3):170-184.

33. Carney $T$, Weber $D$. Public health intelligence: learning from the ebola crisis. Am J Public Health. 2015;105(9):1740-1744.

34. Dickmann P, McClelland A, Gamhewage G, Portela de Souza $P$, Apfel F. Making sense of communication interventions in public health emergencies - an evaluation framework for risk communication. J Commun Healthc. 2015;8(3):233-240. 